\title{
ALS2/Alsin Knockout Mice and Motor Neuron Diseases
}

\author{
Huaibin Cai Hoon Shim Chen Lai Chengsong Xie Xian Lin Wan Jou Yang \\ Jayanth Chandran
}

Laboratory of Neurogenetics, National Institute on Aging, National Institutes of Health, Bethesda, Md., USA

\section{Key Words}

Amyotrophic lateral sclerosis $\cdot$ ALS2 $\cdot$ Alsin $\cdot$ Knockout mice $\cdot$ Mouse model $\cdot$ Guanine nucleotide exchange factor $\cdot$ Primary lateral sclerosis $\cdot$ Hereditary spastic paraplegia

\begin{abstract}
Autosomal recessive mutations in the ALS2 gene have been linked to juvenile-onset amyotrophic lateral sclerosis (ALS2), primary lateral sclerosis and juvenile-onset ascending hereditary spastic paraplegia. Except for two recently identified missense mutations, all other mutations in the ALS2 gene lead to a premature stop codon and likely abrogate all the potential functions of alsin, the protein encoded by the ALS2 gene. To study the pathologic mechanisms of $A L S 2$ deficiency, four different lines of $A L S 2$ knockout $\left(A L S 2^{-1-}\right)$ mice have been generated by independent groups. The loss of ALS2/alsin does not have a drastic effect on the survival or function of motor neurons in mice. However, subtle deficits observed in the behavior and pathology of these mice have aided in our understanding of the relationship between alsin and motor neuron dysfunction. In this review, we summarize and reconcile major findings of $A L S 2^{-/-}$mice and attempt to place these results within the larger context of modeling recessive movement disorders in mice.
\end{abstract}

Copyright $\odot 2008$ S. Karger AG, Base

\section{KARGER}

Fax +41613061234 E-Mail karger@karger.ch www.karger.com
(C) 2008 S. Karger AG, Basel

\section{Introduction}

Amyotrophic lateral sclerosis (ALS), the most common motor neuron disease, lies within a spectrum of heterogeneous syndromes that lead to the selective degeneration of upper or lower motor neurons [1]. Unlike ALS, where both the upper and lower motor neurons are specifically compromised, only the upper motor neurons are affected in primary lateral sclerosis (PLS) and hereditary spastic paraplegia (HSP) [2]. Mutations in the abundant free radical scavenging enzyme, superoxide dismutase 1 (SOD1), were first described 13 years ago, and account for nearly $20 \%$ of all familial ALS [3]. Since the identification of SOD1, four other genes causative for ALS have been identified, and at least six other loci have been mapped, with the majority of the pedigrees carrying dominant modes of inheritance [4]. These genetic links are excellent tools for studying motor neuron disease, since the sporadic and familial forms appear to share a common pathogenesis based on their similar clinical and histopathological phenotypes. To date, only two loci have been mapped that carry autosomal recessive forms of ALS, and of these, only mutations in the gene ALS2, linked to chromosome $2 \mathrm{q} 33$, have been identified $[2,5]$. To date, at least 12 different mutations in the 34 exons of the ALS2 gene have been described in African and Asian families with juvenile ALS and PLS, and in European and Asian families with HSP (fig. 1). With the exception of two recently identified homozygous missense mutations at the amino terminal $[6,7]$, the majority of mutations lead to the generation of

Dr. Huaibin Cai

Unit of Transgenesis, Laboratory of Neurogenetics, National Institute on Aging

National Institutes of Health, Building 35, Room 1A116, MSC 3707

35 Convent Drive, Bethesda, MD 20892-3707 (USA)

Tel. +1 301402 8087, Fax +1 301480 2830,E-Mail caih@mail.nih.gov 
Fig. 1. Domain structure and diseaselinked mutations of alsin. A schematic presentation of linear structure of fulllength alsin and 3D structure models of predicated alsin functional domains. Known disease-linked mutations are also depicted. The 'fs' represents frame-shift, and 'st' represents non-sense mutation that leads to stop codon.

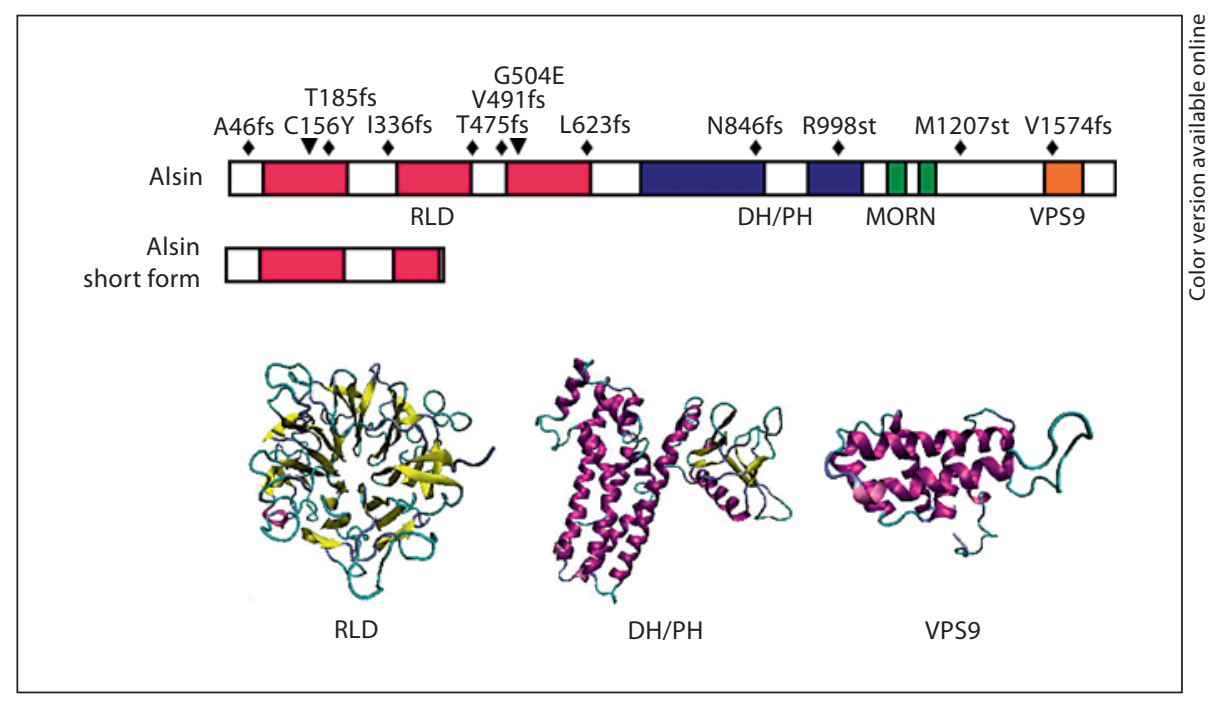

a premature stop codon, resulting in protein instability and loss of function of alsin, the protein encoded by the ALS2 gene [8]. The relationship between the missense mutations and alsin function is unclear.

Alsin, encoded by the full-length ALS2 gene, is predicted to have a molecular mass of $184 \mathrm{kDa}$, and has three putative guanine nucleotide exchange (GEF) domains: a regulator of chromosome condensation 1 (RCC1)-like domain (termed RLD), a diffuse B-cell lymphoma (Dbl) homology/pleckstrin homology $(\mathrm{DH} / \mathrm{PH})$ domain, and a vacuolar protein sorting 9 (VPS9) domain (fig. 1). Additionally, eight consecutive membrane occupation and recognition nexus (MORN) motifs have been identified in the region between the DH/PH and VPS9 domains $[2,5]$. The short splicing variant of alsin only contains part of the RLD domain (fig. 1). Of the reported mutations to date, only four found in the RCC1 domain region are expected to affect both forms of the protein, and of these, the two nearest to the amino-terminus result in frameshift mutations that are responsible for the development of juvenile ALS (ALS2). This observation has led to the speculation that an intact short form of alsin may protect lower motor neurons and be responsible for the varying severity of clinical phenotypes [2]. However, there have been a number of observations since the initial two reports identified disease-causing mutations that suggest that a simple genotype-phenotype correlation may not exist for these ALS2 cases. Nearly half of the patients in the Tunisian kindred that developed juvenile ALS through ALS2 mutations did not show EMG denervation, a diagnostic criteria for lower motor neuron degeneration [9]. Additionally, the 1130delAT mutation affects both the long and short forms of the alsin protein, yet it leads to the development of infant-onset HSP without affecting the lower motor neurons [10]. An in vitro study on the stability of each of the truncated proteins generated by the disease-causing mutations found that all of the mutants were unstable, and surprisingly, they decayed at a half-life comparable to the equally unstable alsin short form, further suggesting that the splicing variants may be an unsuitable marker for clinical phenotype [8]. Furthermore, since no truncated forms of alsin were detected in the lymphoblasts derived from ALS2 patients [8], it excludes the potential gain of toxic function of these truncated proteins, suggesting that ALS2 and related motor neuron diseases are caused by the loss of function of alsin.

After the identification of the first mutations in ALS2, six independent studies on $A L S 2^{-/-}$mice have since been published [11-16]. In this review, we summarize these recent findings related to $A L S 2^{-/-}$mice and attempt to provide a perspective on the emerging pathways that may link the different forms of motor neuron diseases.

\section{Generation of $\boldsymbol{A L S 2}^{-/-}$Mice}

ALS2 mRNA is ubiquitously expressed in the central nervous system and non-neuronal tissues, with the cerebellum and kidney showing the highest enrichment, and spinal cord and heart showing the lowest $[2,5]$. With the exception of the liver, which appears to show selective augmentation of the short form, the distribution of both splice variants appears to be similar at the mRNA level. Interestingly, the short splicing variant of the mouse 
Table 1. Generation of $A L S 2^{-/-}$mice

\begin{tabular}{llll}
\hline Group & $\begin{array}{l}\text { DNA } \\
\text { source }\end{array}$ & $\begin{array}{l}\text { ES cells } \\
\text { substrain }\end{array}$ & $\begin{array}{l}\text { Exon(s) } \\
\text { disrupted }\end{array}$ \\
\hline Cai [11] & 129X1 & $129 \mathrm{X} 1$ & 3 \\
Hadano [12] & $129 \mathrm{X} 1$ & $129 \mathrm{P} 2$ & 3 \\
Devon [13] & NA & $129 \mathrm{~S} 1$ & 3 and 4 \\
Yamanaka [14] & 129S6 & $129 \mathrm{S6}$ & 4 \\
Julien [15] & NA & NA & 2 and part of 3 \\
Deng [16] & 129S6 & $129 S 6$ & 4 and part of 3 \\
\hline
\end{tabular}

$\mathrm{NA}=$ No information available.

ALS2 gene is longer than the human counterpart, which contains the first 13 exons of the ALS2 gene and encodes the entire RLD domain of alsin $[12,14]$. Protein expression largely mirrors mRNA expression, although the short form is undetectable, possibly due to a short halflife $[8,12,14,17]$.

To completely abolish all of the potential functional domains of alsin, all six studies chose to disrupt exons 2-4 of the ALS2 gene to generate the knockout mice (table 1) [1114]. Cai and Hadano used the same gene targeting strategy in which they deleted and replaced the 39 base-pair BamHI fragment in exon 3 of the ALS2 gene with a neomycin gene selection cassette. Devon deleted and replaced ALS2 exons 3 and 4 with a promoter trap vector, and Yamanaka inserted a stop codon in exon 4 and replaced the remaining $3^{\prime}$ of exon 4 and a portion of intron 4 of the ALS2 gene with the neomycin gene. Julien and Deng replaced exon 2 and part of exon 3, and exon 4 and part of exon 3 with the neomycin cassette, respectively. For the source of DNA used in constructing the targeting vectors, Cai and Hadano used the DNA from 129X1/SvJ (129X1) substrain, and Yamanaka and Deng used the DNA from 129S6/SvEvTac (129S6) substrain. The origin of Devon and Julien's DNA constructs is unclear. All mice used in the six studies are of C57BL/6 and 129 hybrid background. It appears that different substrains of mouse embryonic stem (ES) cell lines were also used by the four groups for gene targeting, including lines 129X1 (Cai), 129P2/Ola (129P2, Hadano), 129S1/SvImJ (129S1, Devon) and 129 S6 (Yamanaka and Deng). Since 129 substrains vary extensively in their genomes ( $43 \%$ of loci contain polymorphism among the 129 substrains, compared to $65 \%$ of polymorphism between 129 substrains and C57BL/6J [18]), the different substrains of ES cells used in these four publications may partially contribute to discrepant phenotypes observed from different lines of $A L S 2^{-/-}$mice.

ALS2/Alsin Knockout Mice and Motor Neuron Diseases
To confirm a complete abolishment of alsin expression, different antibodies against either the N- or C-terminals of alsin were used in these four papers; no fulllength nor truncated alsin was detected in all six lines of $A L S 2^{-/-}$mice [11-14]. Although an undetectable level of either $\mathrm{N}$ - or C-terminal truncated alsin may exist in these mice, it is very unlikely to contribute to the knockout phenotypes.

\section{General Observations on ALS2 ${ }^{-/-}$Mice}

$A L S 2^{-/-}$mice are viable, fertile, and display no obvious developmental abnormalities. Offspring derived from heterozygous crosses are born in normal mendelian distribution. Because muscle wasting and the resultant body weight loss are often associated with the onset of motor neuron diseases [19], the body weights of $A L S 2^{-/-}$mice were monitored by all four groups. Cai found that male $A L S 2^{-/-}$mice were significantly heavier compared to wild-type littermates after 12 months of age [11]. The body weights of ALS2 heterozygous knockout mice were between the ALS2 homozygous knockout and wild-type littermates, suggesting an alsin dose-dependent effect on body weight control [11]. A trend of increasing body weight was also observed by the other groups, but it did not reach statistical significance. In addition, Hadano et al. [12] observed a number of female $A L S 2^{-/-}$mice exhibiting excessive body weight. Since all $A L S 2^{-/-}$mice used in these four papers have a 129 and C57BL/6J hybrid background, and C57BL/6J mice display a high susceptibility to diet-induced obesity, it may be necessary to breed knockout mice with a C57BL/6J congenic background and use the same diet to determine if alsin affects body weight control.

\section{Motor Behavior of $\mathrm{ALS2}^{-/-}$Mice}

To identify potential motor behavior abnormalities associated with $A L S 2^{-/-}$mice, Cai applied the primary screen of the SHIRPA test battery [20] to a cohort of 12month-old $A L S 2^{-/-}$mice and their wild-type littermates. $A L S 2^{-/}$mice displayed normal gait, grip, muscle tone, and startle response. Cai found that $A L S 2^{-/-}$mice traveled significantly less distance within the first 30 s than $A L S 2^{+/+}$ mice when transferred to a novel arena. Devon observed a similar reduction of locomotor activity for their knockout mice in the open-field test, which lasted for $3 \mathrm{~min}$. However, when Cai tested the same cohort of mice in the 
Table 2. Behavioral phenotypes of $\mathrm{ALS}^{-{ }^{--}}$mice

\begin{tabular}{llllll}
\hline Group & $\begin{array}{l}\text { Motor } \\
\text { coordination }\end{array}$ & $\begin{array}{l}\text { Motor } \\
\text { learning }\end{array}$ & $\begin{array}{l}\text { Locomotor } \\
\text { activities }\end{array}$ & Anxiety & $\begin{array}{l}\text { Running } \\
\text { speed }\end{array}$ \\
\hline Cai [11] & Decrease & Decrease & NS & Increase & NA \\
Hadano [12] & Decrease NS & NA & NS & NA & NA \\
Devon [13] & NS & NA & Decrease & NA & NA \\
Yamanaka [14] & Decrease & NS & NS & NA & Decrease \\
Julien [15] & Decrease & NA & NA & NA & NA \\
Deng [16] & Decrease & NA & NA & NA & NA \\
\hline
\end{tabular}

NS = Not statistically significant; NA = data not available.

${ }^{1}$ May relate to higher anxiety-induced reduction of exploratory activity. open-field test for $30 \mathrm{~min}$, they failed to detect any reduction in locomotor activities in $A L S 2^{-/-}$mice at both 12 and 20 months of age (table 2). Consistent with Cai's studies, Hadano monitored the movement of $A L S 2^{-/-}$mice in their home cage for a prolonged period and did not detect any significant change in locomotor activities. Later, Cai demonstrated that the decrease in locomotor activity of knockout mice in the SHIRPA test is due to an increased anxiety response to a novel environment when they were first introduced to the test chamber.

In addition to the alteration of anxiety response, Cai and Deng found $A L S 2^{-/-}$mice perform poorly in the rotarod test for motor coordination starting from 12 months of age (table 2). In the same experimental paradigm, Yamanaka found that $A L S 2^{-/-}$mice began to show a motor coordination problem at 5 months of age that worsened at 16 months of age. However, Hadano and Devon did not observe a similar motor coordination deficit in their knockout mice. That the acceleration of the rotating rod in Hadano's experiment was much faster compared to Cai's and Yamanaka's may explain the different result in Hadano's paper. Cai also found that $A L S 2^{-/}$mice displayed motor learning deficits at 20 months of age, indicating that alsin, which is most abundant in the cerebellum $[5,8]$, may participate in cerebellum-dependent motor learning. Yamanaka ran a similar motor learning test for their mice at 5 and 16 months of age, but did not find any significant alterations in motor learning. Thus, it appears that the onset of motor learning deficit is quite late in $A L S 2^{-/-}$mice. Yamanaka also observed a decrease in the running speed of $A L S 2^{-/-}$mice in the running wheel test starting from 5 months of age. No similar test has been done on other ALS2 ${ }^{-/-}$mice.

In summary, motor behavioral studies indicate that $\mathrm{ALS2}^{-/-}$mice display reduced locomotor activity initially in a novel environment due to higher anxiety, exhibit a motor coordination deficit in the rotarod test, and show reduced running speed in the running wheel test (table 2). The lack of overt motor phenotypes in $A L S 2^{-/-}$ mice may reflect differences in the organization of the human and mouse motor systems. For example, the axons of upper motor neurons in humans descend through the lateral cortical spinal tract and directly innervate lower motor neurons in the spinal cord to control the movement. In rodents, there is no direct synaptic connection between the lower and upper motor neurons, as upper motor neurons send their axons mostly through the ventral medial cortical spinal tract and make synapses with the interneurons in the spinal cord [21]. As revealed by previous genetic and clinical studies [2, 9, 22-24], most mutations in ALS2 preferentially affect the upper motor neurons. Conceivably, the anatomical and potentially physiological discrepancy between the human and mouse upper motor neurons may explain the relatively normal motor phenotype of the aged $A L S 2^{-/-}$mice.

The absence of severe motor phenotypes in $\mathrm{ALS2}^{-/-}$ mice may also be related to gene redundancy, in which genes with the similar function could compensate for the loss of function of alsin. Recently, an alsin-related protein (ALS2CL) has been characterized, which is highly homologous to the C-terminal half of alsin, including the MORN motif and VSP9 domain [25]. ALS2CL has higher binding affinity to Rab5 than alsin, but it does not exhibit Rab5-GEF activity. Co-expression of ALS2CL and Rab5 in HeLa cells induces the reorganization of Early endosomal antigen 1 (EEA1)-negative endosomes by forming tabulated structures [25]. In contrast, co-expression of ALS2 and Rab5 induces the enlargement of EEA1positive endosomes [17], suggesting that ALS2 and ALS2CL play different roles in Rab5-mediated endosomal trafficking. Thus, whether ALS2CL can compensate for the loss of alsin remains to be established. 
Table 3. Pathological abnormalities of ALS2 $2^{-/-}$mice

\begin{tabular}{llllll}
\hline Group & CSMN & CST & SMN & VR & Purkinje cells \\
\hline Cai [11] & NS & NA & NS & NA & NS \\
Hadano [12] & NS & NA & NS & Reduced $^{1}$ & Reduced $^{2}$ \\
Devon [13] & Soma size & NA & NS & NS & NS \\
& reduced & & & & \\
Yamanaka [14] & NS & Swollen, degenerating & NS & NS & NS \\
Julien [15] & NA & Degeneration & NA & NA & NA \\
Deng [16] & NS & Degeneration & NS & NA & NA \\
\hline
\end{tabular}

CSMN = Corticospinal motor neurons; CST = corticospinal track; SMN = spinal motor neuron; $\mathrm{VR}=$ ventral root.

${ }^{1}$ Small caliber axons. ${ }^{2}$ Calbindin-positive.

\section{Pathology of $\mathrm{ALS2}^{-/-}$Mice}

Consistent with the modest motor behavioral deficits observed in $A L S 2^{-/-}$mice, no major neuropathological abnormalities have been found in these animals (table 3 ). No significant difference has been observed in the numbers of cortical or spinal motor neurons between $A L S 2^{-/-}$ and wild-type control mice. While all the $A L S 2^{-/-}$models failed to demonstrate any loss of upper or lower motor neurons, Hadano found a decrease in the number of small caliber axons $(1.4-4.5 \mu \mathrm{m})$ in the ventral root of $A L S 2^{-/-}$ spinal cord at 18 months of age. However, Yamanaka only found a trend of insignificant decrease of large caliber axons in the ventral root of knockout mice. Yamanaka instead observed a significant increase of swollen and degenerating axons predominantly in the lateral column of $A L S 2^{-/-}$spinal cord at 16 months of age. Approximately $20 \%$ of the corticospinal tract (CST) projects along the lateral column of spinal cord in mice, while the majority of CST rests at the dorsal medial columns. Julien performed electron microscopy (EM) study on the CST and revealed the presence of degenerative axons in CST of $\mathrm{ALS}^{-/-}$mice at 18 months of age. Most recently, Deng provided evidence of a significant degeneration at dorsal $\mathrm{CST}$ in $A L S 2^{-/-}$mice by amino-cupric-silver staining. However, those studies are short to demonstrate that the degenerating axons indeed belong to the CST. In the future, it may directly examine whether the axonal degeneration in the CST of $A L S 2^{-/-}$mice by labeling the CST with anterograde tracers, such as biotinylated dextranamine, or crossing with transgenic mice that express histological markers in CST.

Hadano found that calbindin-positive Purkinje cells were significantly decreased in $A L S 2^{-/-}$mice at 18 months of age. The soma size of $A L S 2^{-/-}$Purkinje cells was also significantly decreased. However, other groups could not detect similar changes in Purkinje cells of $A L S 2^{-/-}$mice. Devon also reported a reduced soma size of layer $\mathrm{V}$ pyramidal neurons in the sensory motor cortex of $A L S 2^{-/-}$ mice, which has not been confirmed by the other groups.

Hadano also revealed a redistribution of type I slow muscle fibers and altered neuromuscular junctions in aged $A L S 2^{-/-}$mice, which correlates with changes in single motor unit potential and motor unit number estimation analyses. However, Cai did not detect any significant degree of denervation potential by needle electromyography in $A L S 2^{-/-}$mice at 21 months of age. In addition, the grip strength of $A L S 2^{-/-}$mice appeared normal [11, 14]. Therefore, it remains to be confirmed if there is any degeneration in neuromuscular junctions and muscle in the different groups' $A L S 2^{-/}$mice.

Microgliosis and astrocytosis markers were used by all four groups to assess inflammatory responses in the spinal cord and cortical sections of $A L S 2^{-/-}$mice. Only Hadano detected increased gliosis in $A L S 2^{-/-}$mice.

In summary, degeneration of CST is the most consistent pathology observed in multiple lines of $A L S 2^{-/-}$mice. It could be worthwhile to re-examine the functional and morphological alterations of upper motor neurons following CST degeneration in different $A L S 2^{-/}$mice strains in the future, because most ALS2-related mutations led to upper motor neuron disease and previous clinical study suggested a potential denervation of CST in the spinal cord of ALS2 patients [10].

\section{Rab5-Dependent Endocytosis in ALS2-Deficient Cells and Neurons}

Multiple in vitro biochemical and cell biology assays suggest that alsin dysfunction affects endosomal trafficking through a Rab5 small GTPase family-mediated mech- 
anism $[12,13,17,26]$. However, the role of alsin in Rab5mediated endosomal fusion remains controversial. To determine whether alsin activates Rab5 and promotes endosomal fusion, several groups have transfected fulllength or truncated forms of alsin containing either the VPS9 domain alone, or the VPS9 domain with other domains. While all forms of alsin could stimulate the release of bound GDP from Rab5 subfamily GTPases in a cellfree GDP dissociation assay, overexpressed full-length alsin was unable to stimulate Rab5-mediated endosomal fusion as efficiently as truncated forms lacking the chromosome condensation 1 (RCC1)-like domains (RLD) [17, 26]. Analyses of a range of alsin deletion constructs suggest that multiple domains influence Rab5-GEF activity. While an N-terminal fragment lacking the VPS9 domain unsurprisingly lacks Rab5 GEF activity, C-terminal peptides containing solely the VPS9 are also unable to promote Rab5 GEF activity [17]. This interplay between alsin domains in regulating Rab5 activity results in interesting observations on the endocytic pathway. Overexpression of wild-type Rab5A (Rab5) in cell lines promotes endosomal fusion, resulting in the formation of large endosomal structures. The degree of fusion is enhanced if a constitutively active form of Rab5 (Rab5Q) is expressed instead of Rab5 [27]. Co-expression of Rab5 and a truncated alsin construct with solely MORN motifs and the VPS9 domain fail to replicate the enhanced endosomal fusion observed with the Rab5Q construct alone [17]. This difference, however, is mitigated if the $\mathrm{DH} / \mathrm{PH}$ domain is included with the MORN motifs and VPS9 domain, suggesting that the $\mathrm{DH} / \mathrm{PH}$ domain has a role in enhancing Rab5 activity as well [17]. While much of the current literature suggests that $\mathrm{DH} / \mathrm{PH}$ and VPS9 domains with the MORN motifs are necessary to promote Rab5 activity in the endocytic pathway, a regulatory role for the RLD domain has been also proposed [17]. Recently, two motor neuron disease-related missense mutations $(\mathrm{C} 156 \mathrm{Y}$ and G540E) have been identified within the RLD domain, indicating that this domain also plays a very important role in the normal function of alsin [6, 7]. The RLD domain consists of a seven-bladed propeller formed from internal amino acid repeats [28]. When only the RLD domain of alsin is expressed in cell lines, a diffuse staining pattern similar to full-length alsin overexpression is observed, indicating a cytosolic distribution $[17,26]$. Expression of alsin lacking the RLD domain in cell lines, on the other hand, results in extensive vesicular localization associated with early endosome markers $[8,17]$. Therefore, the RLD domain of alsin may prevent the association of activated Rab5 with its downstream effectors located in early endo- somes, suggesting that this domain acts as a negative regulator of Rab5-mediated endosomal fusion.

Generation of $A L S 2^{-/-}$mice makes it possible to study the role of alsin in Rab5-dependent endocytosis in vivo. In support of alsin's role in promoting Rab5-dependent early endosomal fusion, Devon showed that the cytosol prepared from $A L S 2^{-/-}$mouse brains exhibited significantly reduced endosomal fusion activities in a cell-free assay [13]. However, this observation is not supported by their own cell-based endocytic studies in alsin-deficient neurons [13]. Furthermore, Devon found that the accumulation of enlarged insulin-like growth factor 1 (IGF1) receptor-containing early endosomes following IGF1 treatment was 1,000 times higher in $A L S 2^{-/-}$neurons as compared to wild-type controls [13]. In addition, Hadano reported that $A L S 2^{-/-}$fibroblasts treated with epithelium growth factor (EGF) showed a delay in EGF receptor-mediated endocytosis, which is supported by a similar study on neurons treated with brain-derived growth factor by Devon $[12,13]$.

In summary, the dynamics of endosomal transport and fusion appear to be compromised in cells derived from $\mathrm{ALS2}^{-/-}$mice. However, since alsin is also an activator of Racl GTPase [26, 29], and Racl is involved in growth factor-induced endocytosis [30], it is not clear that the delayed endocytic responses in $A L S 2^{-/-}$cells is due to the dysfunction of a Rab5 or Rac1-dependent pathway.

\section{Alsin as a Risk Factor}

One of the observations in post-mortem tissue from sporadic ALS patients is oxidative damage to proteins, lipids, and DNA [31]. Although it remains unclear whether oxidative stress plays a primary role in the progression of ALS, aberrant production of reactive oxygen species and nitrogen species may contribute to the demise of motor neurons. In vitro studies showed that alsin plays a protective role against mutant SOD1-mediated cell death through a Rac1/ phosphatidylinositol-3 kinase/Akt3 antiapoptotic pathway, which is also involved in the antioxidative stress response in cells [32]. In line with these studies, Cai found that the loss of ALS2 rendered neurons more vulnerable to oxidative stress. However, no obvious effects from the loss of alsin on motor neuron degeneration or survival in SOD1 ${ }^{\mathrm{G} 93 \mathrm{~A}}$ transgenic mice was observed, suggesting that alsin plays a very limited role in protecting spinal motor neurons from SOD1-mediated toxicity in vivo [33]. 
Alsin also seems to protect neurons from glutamatemediated excitotoxicity [34]. Glutamate-mediated excitotoxicity, primarily by $\alpha$-amino-3-hydroxy-5-methyl-4isoxazolepropionate (AMPA)-type glutamate receptors (AMPAR) in spinal motor neurons, contributes to the sporadic ALS [35]. AMPARs are tetramers composed of various combinations of GluR1-4 subunits. GluR2 is particularly important since GluR2-containing AMPARs are calcium-impermeable, and neurons lacking GluR2-containing AMPARs are more vulnerable to excitotoxicity [35]. The presentation of GluR2 at the synaptic surface is dynamically regulated through its binding proteins, including glutamate receptor interacting protein 1 (GRIP1). GRIP1 transports GluR2 to dendrites and anchors GluR2 to both postsynaptic membrane and intracellular compartments [36, 37]. The RLD domain of alsin appears to interact with the PSD-95/Dlg/ZO-1 (PDZ) domains of GRIP1, and loss of alsin alters the subcellular localization of GRIP1. This correlates with a reduction of GluR2 at the cell/synaptic surface of $A L S 2^{-/-}$neurons, resulting in an increased vulnerability of these neurons to excitotoxicity. This study reveals a novel function of alsin in AMPAR trafficking and provides a novel molecular pathway linking alsin deficiency with motor neuron degeneration, which may serve as a therapeutic target for the treatment of ALS2 and related motor neuron diseases.

\section{Conclusions}

Four different lines of $A L S 2^{-/-}$mice have been generated independently with variations in targeting vector, ES cell line, and probably housing conditions. As a result, while several observations are relatively conserved across the different reported mouse knockouts, some discrepancies are notable and help illustrate the difficulties in assigning phenotypes to mouse models. Unlike the striking behavioral and pathological phenotypes generated from transgenic mice overexpressing mutations in SOD1 [4], $A L S 2^{-/-}$mice do not develop overt motor neuron disease caused by substantial motor neuron degeneration [11-14]. However, $\mathrm{ALS}^{-/-}$mice did show signs of CST degeneration [14], which is consistent with previous clinical observations of potential denervation of CST in ALS2 patients [10]. Although the exact mechanism is unclear, the lack of overt motor and pathological phenotypes in $\mathrm{ALS2} 2^{-/-}$mice may reflect the intrinsic differences between humans and mice, including lifespan and organization of motor systems, and may also relate to gene redundancy by which ALS2CL may compensate for the loss of alsin function. It is not wholly surprising that many mouse knockouts fail to recapitulate major neuropathological phenotypes of autosomal recessive neurodegenerative diseases. For example, parkin and DJ-1 knockout mice, which model two different types of autosomal recessive Parkinson's disease, do not develop the typical pathological hallmarks of Parkinson's disease: Lewy body formation and nigrostriatal dopaminergic neuron degeneration [38]. While it remains a challenge to model a recessive neurodegenerative disease in mice, genetic ablations of parkin, DJ-1, and PINK1 in fruit flies result in more obvious behavioral and pathological phenotypes $[39,40]$. Therefore, it would be of interest to generate alsin-null flies and zebrafish as alternative animal models for ALS2. In addition, it would also be very interesting to examine whether the two ALS2-related missense mutations (C156Y and G540E) [6, 7] affect the normal function of alsin through either a loss of function or a dominate negative mechanism. The generation of ALS2 C156Y or G540E knock-in mice would be helpful to address this question.

Despite the lack of desired behavioral and pathological phenotypes in $A L S 2^{-/-}$mice, $A L S 2^{-/-}$neurons are very useful for the study of the physiological function of alsin and how it contributes to the function and survival of motor neurons. Alsin-deficient neurons and fibroblasts have been used to examine the Rab5-dependent endocytic pathway $[12,13]$. More recently, Lai et al. [34] show that alsin is involved in synaptic targeting of glutamate receptors through interaction with GRIP1, and $A L S 2^{-/-}$ motor neurons are more susceptible to excitotoxicity, likely due to a decrease of calcium-impermeable glutamate receptors in the synapses. Needless to say, there are functions of alsin that remain to be discovered, which will help us reach a better understanding of this interesting protein and motor neuron diseases in general.

\begin{tabular}{|c|c|c|}
\hline References & $\nabla_{3}$ & $\begin{array}{l}\text { Cleveland DW, Rothstein JD: From Charcot } \\
\text { to Lou Gehrig: deciphering selective motor } \\
\text { neuron death in ALS. Nat Rev Neurosci } \\
\text { 2001;2:806-819. } \\
\text { Yang Y, Hentati A, Deng HX, Dabbagh O, } \\
\text { Sasaki T, Hirano M, Hung WY, Ouahchi K, } \\
\text { Yan J, Azim AC, Cole N, Gascon G, Yagmour } \\
\text { A, Ben Hamida M, Pericak-Vance M, Hen- } \\
\text { tati F, Siddique T: The gene encoding alsin, a } \\
\text { protein with three guanine-nucleotide ex- } \\
\text { change factor domains, is mutated in a form } \\
\text { of recessive amyotrophic lateral sclerosis. } \\
\text { Nat Genet 2001;29:160-165. } \\
\text { Rosen DR: Mutations in Cu/Zn superoxide } \\
\text { dismutase gene are associated with familial } \\
\text { amyotrophic lateral sclerosis. Nature 1993; } \\
\text { 364:362. }\end{array}$ \\
\hline
\end{tabular}

Neurodegenerative Dis 2008;5:359-366 365 
-4 Bruijn LI, Miller TM, Cleveland DW: Unraveling the mechanisms involved in motor neuron degeneration in ALS. Annu Rev Neurosci 2004;27:723-749.

-5 Hadano S, Hand CK, Osuga H, Yanagisawa Y, Otomo A, Devon RS, Miyamoto N, Showguchi-Miyata J, Okada Y, Singaraja R, Figlewicz DA, Kwiatkowski T, Hosler BA, Sagie T, Skaug J, Nasir J, Brown RH Jr, Scherer SW, Rouleau GA, Hayden MR, Ikeda JE: A gene encoding a putative GTPase regulator is mutated in familial amyotrophic lateral sclerosis 2. Nat Genet 2001;29:166-173.

-6 Panzeri C, De Palma C, Martinuzzi A, Daga A, De Polo G, Bresolin N, Miller CC, Tudor EL, Clementi E, Bassi MT: The first ALS2 missense mutation associated with JPLS reveals new aspects of alsin biological function. Brain 2006;129:1710-1719.

-7 Eymard-Pierre E, Yamanaka K, Haeussler M, Kress W, Gauthier-Barichard F, Combes P, Cleveland DW, Boespflug-Tanguy O: Novel missense mutation in $A L S 2$ gene results in infantile ascending hereditary spastic paralysis. Ann Neurol 2006;59:976-980.

-8 Yamanaka K, Vande Velde VC, EymardPierre E, Bertini E, Boespflug-Tanguy O, Cleveland DW: Unstable mutants in the peripheral endosomal membrane component ALS2 cause early-onset motor neuron disease. Proc Natl Acad Sci USA 2003;100: 16041-16046.

-9 Ben Hamida M, Hentati F, Ben Hamida C: Hereditary motor system diseases (chronic juvenile amyotrophic lateral sclerosis). Conditions combining a bilateral pyramidal syndrome with limb and bulbar amyotrophy. Brain 1990;113:347-363.

10 Eymard-Pierre E, Lesca G, Dollet S, Santorelli FM, Di Capua M, Bertini E, Boespflug-Tanguy $\mathrm{O}$ : Infantile-onset ascending hereditary spastic paralysis is associated with mutations in the alsin gene. Am J Hum Genet 2002;71:518-527.

-11 Cai H, Lin X, Xie C, Laird FM, Lai C, Wen H, Chiang HC, Shim H, Farah MH, Hoke A, Price DL, Wong PC: Loss of ALS2 function is insufficient to trigger motor neuron degeneration in knock-out mice but predisposes neurons to oxidative stress. J Neurosci 2005;25:7567-7574.

-12 Hadano S, Benn SC, Kakuta S, Otomo A, Sudo K, Kunita R, Suzuki-Utsunomiya K, Mizumura H, Shefner JM, Cox GA, Iwakura Y, Brown RH Jr, Ikeda JE: Mice deficient in the Rab5 guanine nucleotide exchange factor ALS2/alsin exhibit age-dependent neurological deficits and altered endosome trafficking. Hum Mol Genet 2006;15:233-250.

-13 Devon RS, Orban PC, Gerrow K, Barbieri MA, Schwab C, Cao LP, Helm JR, Bissada N, Cruz-Aguado R, Davidson TL, Witmer J, Metzler M, Lam CK, Tetzlaff W, Simpson EM, McCaffery JM, El Husseini AE, Leavitt BR, Hayden MR: Als2-deficient mice exhibit disturbances in endosome trafficking associated with motor behavioral abnormalities. Proc Natl Acad Sci USA 2006;103:9595-9600.

14 Yamanaka K, Miller TM, McAlonis-Downes M, Chun SJ, Cleveland DW: Progressive spi- nal axonal degeneration and slowness in ALS2-deficient mice. Ann Neurol 2006;60: 95-104.

15 Julien JP, Kriz J: Transgenic mouse models of amyotrophic lateral sclerosis. Biochim Biophys Acta 2006;1762:1013-1024.

16 Deng HX, Zhai H, Fu R, Shi Y, Gorrie GH, Yang Y, Liu E, Dal Canto MC, Mugnaini E, Siddique T: Distal axonopathy in an alsindeficient mouse model. Hum Mol Genet 2007;16:2911-2920.

17 Otomo A, Hadano S, Okada T, Mizumura H Kunita R, Nishijima H, Showguchi-Miyata J, Yanagisawa Y, Kohiki E, Suga E, Yasuda M, Osuga H, Nishimoto T, Narumiya S, Ikeda JE: ALS2, a novel guanine nucleotide exchange factor for the small GTPase Rab5, is implicated in endosomal dynamics. Hum Mol Genet 2003;12:1671-1687.

18 Simpson EM, Linder CC, Sargent EE, Davisson MT, Mobraaten LE, Sharp JJ: Genetic variation among 129 substrains and its importance for targeted mutagenesis in mice. Nat Genet 1997;16:19-27.

19 Wong PC, Pardo CA, Borchelt DR, Lee MK, Copeland NG, Jenkins NA, Sisodia SS, Cleveland DW, Price DL: An adverse property of a familial ALS-linked SOD1 mutation causes motor neuron disease characterized by vacuolar degeneration of mitochondria. Neuron 1995; 14:1105-1116.

20 Rogers DC, Fisher EM, Brown SD, Peters J, Hunter AJ, Martin JE: Behavioral and functional analysis of mouse phenotype: SHIR$\mathrm{PA}$, a proposed protocol for comprehensive phenotype assessment. Mamm Genome 1997;8:711-713.

21 Yang HW, Lemon RN: An electron microscopic examination of the corticospinal projection to the cervical spinal cord in the rat lack of evidence for cortico-motoneuronal synapses. Exp Brain Res 2003;149:458-469.

22 Hentati A, Bejaoui K, Pericak-Vance MA, Hentati F, Speer MC, Hung WY, Figlewicz DA, Haines J, Rimmler J, Ben Hamida C: Linkage of recessive familial amyotrophic lateral sclerosis to chromosome 2q33-q35. Nat Genet 1994;7:425-428.

23 Eymard-Pierre E, Lesca G, Dollet S, Santorelli FM, Di Capua M, Bertini E, Boespflug-Tanguy O: Infantile-onset ascending hereditary spastic paralysis is associated with mutations in the alsin gene. Am J Hum Genet 2002;71:518-527.

24 Devon RS, Helm JR, Rouleau GA, Leitner Y, Lerman-Sagie T, Lev D, Hayden MR: The first non-sense mutation in alsin results in a homogeneous phenotype of infantile-onset ascending spastic paralysis with bulbar involvement in two siblings. Clin Genet 2003; 64:210-215.

25 Hadano S, Otomo A, Suzuki-Utsunomiya K Kunita R, Yanagisawa Y, Showguchi-Miyata J, Mizumura H, Ikeda JE: ALS2CL, the novel protein highly homologous to the carboxyterminal half of ALS2, binds to Rab5 and modulates endosome dynamics. FEBS Lett 2004;575:64-70.

26 Topp JD, Gray NW, Gerard RD, Horazdovsky BF: Alsin is a Rab5 and Rac1 guanine nucleo- tide exchange factor. J Biol Chem 2004;279: 24612-24623.

27 Li G, Stahl PD: Structure-function relationship of the small GTPase rab5. J Biol Chem 1993;268:24475-24480.

28 Renault L, Nassar N, Vetter I, Becker J, Klebe C, Roth M, Wittinghofer A: The 1.7 A crystal structure of the regulator of chromosome condensation (RCC1) reveals a seven-bladed propeller. Nature 1998;392:97-101.

-29 Jacquier A, Buhler E, Schafer MK, Bohl D, Blanchard S, Beclin C, Haase G: Alsin/Rac1 signaling controls survival and growth of spinal motoneurons. Ann Neurol 2006;60: 105-117.

30 Lanzetti L, Rybin V, Malabarba MG, Christoforidis S, Scita G, Zerial M, Di Fiore PP: The Eps8 protein coordinates EGF receptor signalling through Rac and trafficking through Rab5. Nature 2000;408:374-377.

31 Shaw PJ, Ince PG, Falkous G, Mantle D: Oxidative damage to protein in sporadic motor neuron disease spinal cord. Ann Neurol 1995;38:691-695

32 Kanekura K, Hashimoto Y, Kita Y, Sasabe J, Aiso S, Nishimoto I, Matsuoka M: A Racl/ phosphatidylinositol 3-kinase/Akt3 antiapoptotic pathway, triggered by AlsinLF, the product of the ALS2 gene, antagonizes $\mathrm{Cu} /$ Zn-superoxide dismutase (SOD1) mutantinduced motoneuronal cell death. J Biol Chem 2005;280:4532-4543.

33 Lin X, Shim H, Cai H: Deficiency in the ALS2 gene does not affect the motor neuron degeneration in SOD1(G93A) transgenic mice. Neurobiol Aging 2007;28:1628-1630.

- 34 Lai C, Xie C, McCormack SG, Chiang HC, Michalak MK, Lin X, Chandran J, Shim H, Shimoji M, Cookson MR, Huganir RL, Rothstein JD, Price DL, Wong PC, Martin LJ, Zhu JJ, Cai H: Amyotrophic lateral sclerosis-2 deficiency leads to neuronal degeneration in amyotrophic lateral sclerosis through altered AMPA receptor trafficking. J Neurosci 2006;26:11798-11806.

35 Kwak S, Weiss JH: Calcium-permeable AMPA channels in neurodegenerative disease and ischemia. Curr Opin Neurobiol 2006;16:281-287.

-36 Setou M, Seog DH, Tanaka Y, Kanai Y, Takei Y, Kawagishi M, Hirokawa N: Glutamate-receptor-interacting protein GRIP1 directly steers kinesin to dendrites. Nature 2002;417: 83-87.

37 Song I, Huganir RL: Regulation of AMPA receptors during synaptic plasticity. Trends Neurosci 2002;25:578-588.

38 Fleming SM, Fernagut PO, Chesselet MF: Genetic mouse models of parkinsonism: strengths and limitations. NeuroRx 2005;2: 495-503.

39 Dodson MW, Guo M: Pink1, Parkin, DJ-1 and mitochondrial dysfunction in Parkinson's disease. Curr Opin Neurobiol 2007; 17:331-337.

40 Zhou H, Falkenburger BH, Schulz JB, Tieu K, $\mathrm{Xu} \mathrm{Z}$, Xia XG: Silencing of the Pink1 gene expression by conditional RNAi does not induce dopaminergic neuron death in mice. Int J Biol Sci 2007;3:242-250. 